\title{
Preparation of a Cellulose Column for Enhancing the Sensing Efficiency of the Biocide 2-n-Octyl-4-Isothiazolin-3-One
}

\author{
Seong Ho Hong ${ }^{1}$ and Sang Wook Kang ${ }^{1,2, *}$ \\ 1 Department of Chemistry, Sangmyung University, Seoul 03016, Korea; wkn7836@daum.net \\ 2 Department of Chemistry and Energy Engineering, Sangmyung University, Seoul 03016, Korea \\ * Correspondence: swkang@smu.ac.kr; Tel.: +82-2-2287-5362
}

Received: 28 August 2020; Accepted: 11 November 2020; Published: 16 November 2020

check for updates

\begin{abstract}
In this study, a cellulose acetate (CA) membrane with pores generated by a water pressure treatment was investigated for its ability to serve as a pretreatment filter device for the detection of 2-n-octyl-4-isothiazolin-3-one (OIT). Pores were generated by applying a water pressure of 8 bar to a membrane manufactured using a CA-based polymer solution. The CA used for the manufacturing was an environment-friendly, low-cost and highly energy-efficient material. Furthermore, since the fabricated porous CA polymeric film possessed many hydrophilic functional groups, it could strongly bind hydrophilic substances while avoiding interaction with hydrophobic substances. OIT, which comprises a hydrophobic bond that forms weak bonds over time, can break down more easily than hydrophilic impurities. The different extents of interaction occurring between either the toxic fungicide OIT or the hydrophilic impurities and the CA film were determined by Fourier-transform infrared (FT-IR) spectroscopy. The physicochemical changes in the resulting membrane, which occurred when the pores were generated, were investigated through scanning electron microscopy (SEM) and thermogravimetric analysis (TGA).
\end{abstract}

Keywords: cellulose acetate (CA); 2-n-Octyl-4-Isothiazolin-3-one (OIT); porous membrane; water-pressure; hydrophobic

\section{Introduction}

Porous materials offer many advantages, such as high surface area, energy efficiency, high permeability and low weight [1-6]. Therefore, they have been widely applied for the development of batteries, separation and filtration materials, catalysts for synthesis and heat dissipation sensors, among other applications [7-17].

In a recent study, a porous polybenzimidazole (PBI) membrane was used as a battery separator. This PBI membrane contained numerous amine groups that enabled dendrite-free Li deposition, while exhibiting a stable and low overpotential cycling durability. Furthermore, in order to increase the voltage efficiency, 2,3-epoxypropyltrimethylammonium chloride (EPTMA-Cl) was used as a grafting agent to synthesize the PBI membranes grafted with quaternary ammonium groups $[18,19]$.

In the sensing field, Alrammouza et al. developed a sensor that integrated a graphene oxide detection layer with a paper substrate. This graphene-oxide-based sensor displayed good response to humidity due to the presence of many pores and a high hydrophobicity [20]. Zhang et al. synthesized a super-porous $\mathrm{NiFe}_{2} \mathrm{O}_{4}$ microsphere structure and used it to manipulate a sensor. The porous $\mathrm{NiFe}_{2} \mathrm{O}_{4}$ microspheres were highly sensitive and selective for detecting acetone over other volatile organic gases [21]. Tan et al. produced an optical sensor using a metal-organic framework as a porous material. This photo-responsive adsorbent underwent adsorption and desorption in response to remote 
stimuli, introduced porous materials and allowed for potential energy conversion applications [22]. Rahman et al. detected 3-methoxyphenol (3-MP) using a chemical sensor made of a synthesized $\mathrm{Ag}_{2} \mathrm{O} /$ carbon black nanocomposite (CB NC) that was deposited on a glassy carbon electrode (GCE) [23]. Kopytina et al. used a tetradecylphosphonium salt to detect pertechnetate ions. A sensor based on a polyvinyl chloride (PVC) polymeric matrix membrane successfully quantified pertechnetate ions in radioactive waste [24]. Hierarchical porous $\mathrm{Au} / \mathrm{ZnO}$ microspheres with a diameter of 10-12 $\mu \mathrm{m}$ were used as a $\mathrm{CH}_{4}$ gas sensor. $\mathrm{An} \mathrm{Au} / \mathrm{ZnO}$-based sensor with an $\mathrm{Au}$ content of $1.0 \%$ exhibited a maximum detection performance of 4.16 at $100 \mathrm{ppm}$ of $\mathrm{CH}_{4}$ and $250{ }^{\circ} \mathrm{C}$ [25].

In the gas separation field, Liu et al. employed a polyvinyl-alcohol-polysulfone (PVA-PS) composite membrane for the separation of a $\mathrm{CO}_{2} / \mathrm{N}_{2}$ mixed gas [26]. Neha Tyagi et al. suggested a graphene-based ultra-thin film for gas separation. Furthermore, these nanoporous graphene (NPG) membranes have potential applications in halogen separation [27]. Lei Wang et al. generated a membrane using a synthesized porous aromatic framework-97 (PAF-97) through a one-step, acid-catalyzed reaction. PAF-97 increased the structural flexibility due to the presence of ether functional groups. The selectivity of this membrane for $\mathrm{CO}_{2} / \mathrm{CH}_{4}$ was 22.48 [28]. Anna Ovchrova et al. proposed an ethylene/ethane gas separation process based on polysulfone. Ethylene has a permeability of $185 \mathrm{~L}$ for this membrane. This value was the best result achievable in the porous literature [29].

Soesantoa et al. investigated the performance of powdered activated-carbon dynamic membranes (PAC DMs) for high-efficiency seawater pretreatment. In the contamination mechanism, the seudosteady-state filtration flow rate and the refusal of cross-flow microfiltration was increased by $59 \%$ and $29 \%$, respectively, when PAC DM was used than PAC DM was not used. As a result, this study provided insight into the Fenton oxidation process (FOP) cleaning technology for PAC DM crossflow cleaning, thus enabling the automation and optimization of the DM operation [30].

In this study, we propose a porous cellulose acetate (CA) membrane as a pretreatment filter for the development of 2-n-octyl-4-isothiazolin-3-one (OIT)-sensitive sensor. CA polymer-based films contain many hydrophilic moieties (e.g., ether and carbonyl groups), and hence can be expected to bind hydrophilic impurities, but not OIT. It was based on the method of fabricating a porous material using hydraulic pressure on a membrane made of CA and Ni salts proposed in our laboratory [31]. Films generated in this new way are expected to be applicable to more diverse fields. The water uptake performance of the film was measured to confirm that it could serve as a sensor by strongly adsorbing hydrophilic impurities, except OIT [32]. Fourier-transform infrared (FT-IR) spectroscopy was conducted to investigate the interaction between the membrane and either hydrophilic impurities or OIT. The produced film, which possessed many hydrophilic groups and exhibited excellent water adsorption performance, was found to be a suitable pretreatment filter for the OIT sensors.

\section{Materials and Methods}

\subsection{Materials}

CA (Mn 50,000) was purchased from Aldrich Co. (Darmstadt, Germany). 2-n-Octyl-4-isothiazolin3-one was purchased from Tokyo Chemical Industry Co. (Tokyo, Japan). 2-n-Octyl-4-isothiazolin-3-one is a light-yellow oil, with a molecular weight of $213.34 \mathrm{~g} / \mathrm{mol}$ and a boiling point of $120^{\circ} \mathrm{C}$. Nickel(II) nitrate hexahydrate was obtained from Samchun Pure Chemical Co. (Seoul, Korea). Acetone was acquired from Daejung Chemical \& Metals (Gyeonggi, Korea). All reagents were used without any treatment.

\subsection{Membrane Fabrication}

A $10 \%(w t / w t)$ CA $(\mathrm{Mn} \sim 50,000)$ solution was prepared by dissolving CA in acetone/water $(w t / w t 8: 2)$. The solution was stirred for $3 \mathrm{~h}$, followed by the addition of $0.23 \mathrm{~mol}$ of $\mathrm{Ni}\left(\mathrm{NO}_{3}\right)_{2} \cdot 6 \mathrm{H}_{2} \mathrm{O}$ per mol of $\mathrm{CA}$, and the mixture was stirred for approximately $2 \mathrm{~h}$. The prepared polymer solution was a clear, viscous, cyan liquid, and when the solvent evaporated, the polymer CA precipitated. The solution was coated on a glass plate at $200 \mu \mathrm{m}$, based on the solution state, using the freestanding method for 
membrane fabrication. Subsequently, pore formation was induced in the membrane using a water pressure treatment device at a pressure of 8 bar. The fabricated membrane was dried in a vacuum oven for 2 days.

\subsection{Experimental}

Samples of the contaminant were prepared upon dissolution in ethanol. These solutions were prepared by reducing the amount of 2-n-octyl-4-isothiazolin-3-one per repeating unit mole of CA by $1 / 10$ from $1.0 \times 10^{-1}$ moles. The adsorption extent was measured by FT-IR spectroscopy (VERTEX 70, BRUKER, Billerica, MA, USA).

\section{Results}

\subsection{Water Uptake Data}

A water uptake experiment was conducted to investigate the intensity with which the manufactured membrane interacted with the hydrophilic substances. Upon subjecting a $\mathrm{CA} / \mathrm{Ni}\left(\mathrm{NO}_{3}\right)_{2} \cdot 6 \mathrm{H}_{2} \mathrm{O}$ 1:0.23 membrane to an 8-bar water pressure treatment, it could be expected that the membrane would adsorb water and hydrophilic substances due to the presence of hydrophilic functional groups such as carbonyl and ether moieties. As shown in Figure 1 and Table 1, the results of this water adsorption experiment indicated that the water uptakes by the CA membrane were $45.97 \%, 9.75 \%$ and $1.60 \%$ after 2,4 and $6 \mathrm{~h}$, respectively. Therefore, the CA membrane fabricated using a nickel salt proved to be a highly hydrophilic membrane; consequently, OIT—a hydrophobic substance — was not well adsorbed. Therefore, this membrane may be suitable for use as a pretreatment column to adsorb hydrophilic impurities.

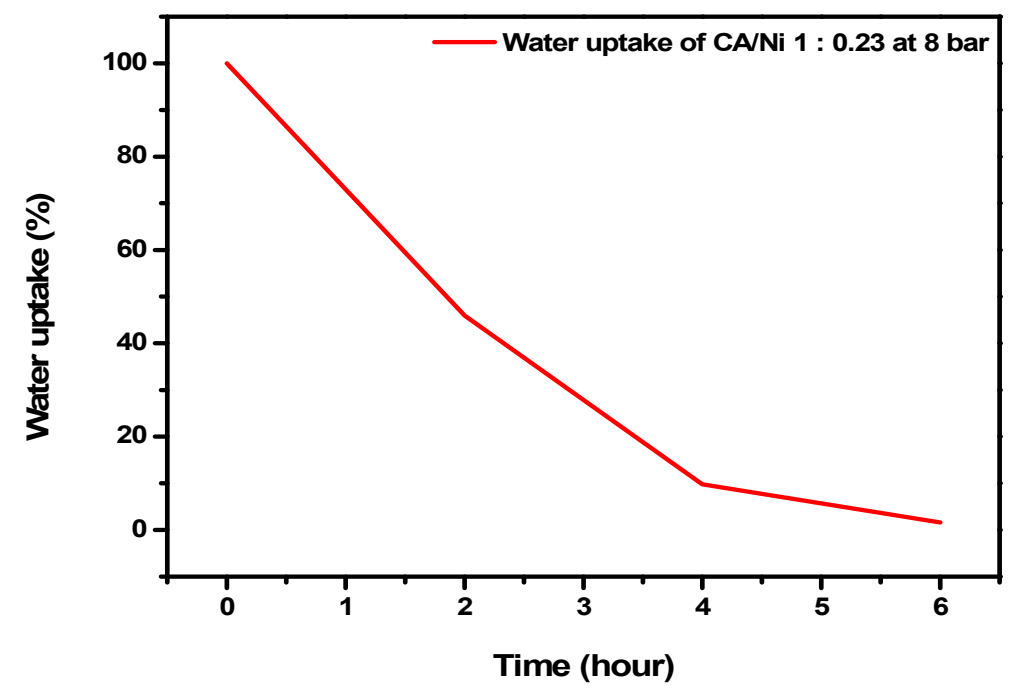

Figure 1. Water uptake data for $\mathrm{CA} / \mathrm{Ni}\left(\mathrm{NO}_{3}\right)_{2} \cdot 6 \mathrm{H}_{2} \mathrm{O}$ measured as a function of time (h).

Table 1. Water uptake data.

\begin{tabular}{cc}
\hline Time (h) & Water Uptake (\%) \\
\hline 0 & 100 \\
2 & 45.95 \\
4 & 9.75 \\
6 & 1.60 \\
\hline
\end{tabular}

\subsection{Scanning Electron Microscope (SEM)}

Scanning electron microscopy (SEM, JEOL JSM-5600LV, JEOL, Tokyo, Japan) was performed to observe the pores on the upper side of the CA membrane. Figure $2 \mathrm{a}-\mathrm{c}$ shows the neat CA $(\mathrm{Mn} \sim 50,000)$ 
without water pressure treatment, 1:0.23 CA/Ni( $\left(\mathrm{NO}_{3}\right)_{2} \cdot 6 \mathrm{H}_{2} \mathrm{O}$ without hydraulic pressure exposure and 1:0.23 CA/Ni( $\left(\mathrm{NO}_{3}\right)_{2} \cdot 6 \mathrm{H}_{2} \mathrm{O}$ membrane after application of a water pressure treatment at 8 bar, respectively. In Figure 2c, the presence of fine pores sized 3-4 $\mu \mathrm{m}$ could be confirmed by observing the surface of the membrane that was subjected to the hydraulic pressure; pore formation led to an increase in the surface area of the membrane. From these results, it was anticipated that the hydrophilic impurities could be well adsorbed through the membrane pores.

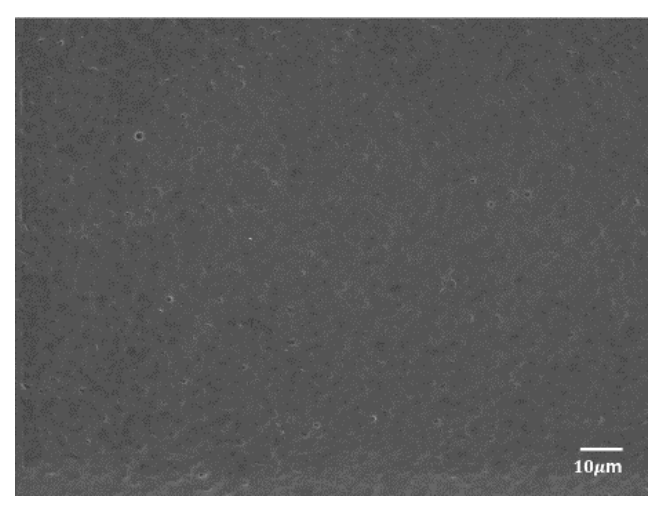

(a)

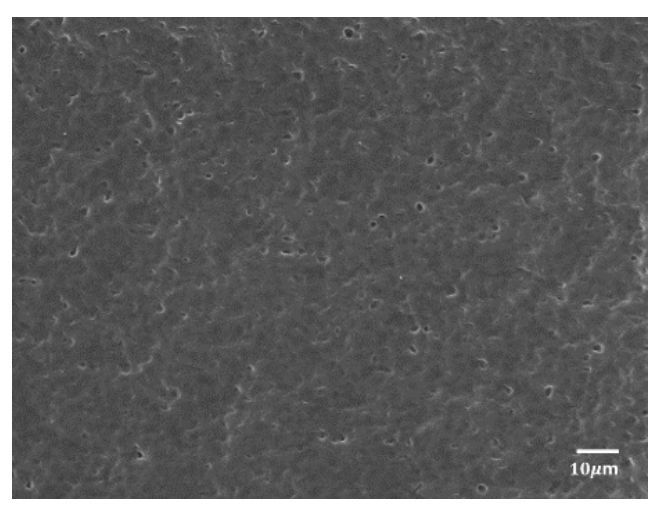

(b)

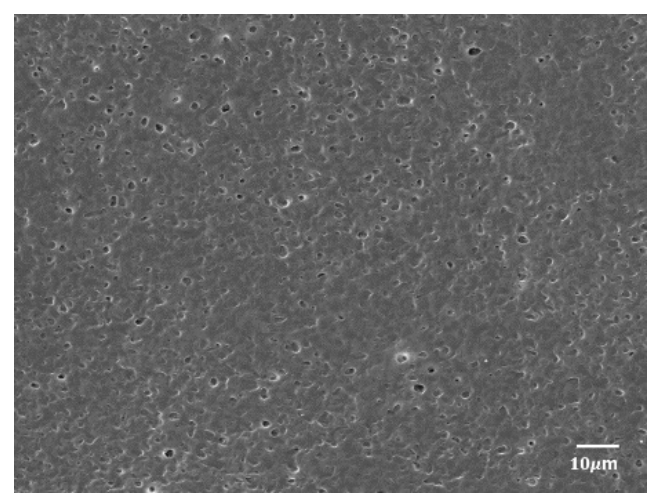

(c)

Figure 2. SEM images of (a) neat $\mathrm{CA},(\mathbf{b})$ 1:0.23 $\mathrm{CA} / \mathrm{Ni}\left(\mathrm{NO}_{3}\right)_{2} \cdot 6 \mathrm{H}_{2} \mathrm{O}$ film dissolved in acetone/water (wt/wt 8:2) before applying a water pressure treatment and (c) 1:0.23 CA/Ni( $\left(\mathrm{NO}_{3}\right)_{2} \cdot 6 \mathrm{H}_{2} \mathrm{O}$ film dissolved in acetone/water (wt/wt 8:2) after water treatment at 8 bar.

Figure 3 shows a cross section of the 1:0.23 CA/Ni( $\left(\mathrm{NO}_{3}\right)_{2} \cdot 6 \mathrm{H}_{2} \mathrm{O}$ membrane after water treatment at 8 bar. The cross section shows a porous morphology that looks sponge-like. The size of the pores 
distributed in the membrane is about $2-4 \mu \mathrm{m}$, and the thickness of the membrane was measured at approximately $35 \mu \mathrm{m}$.

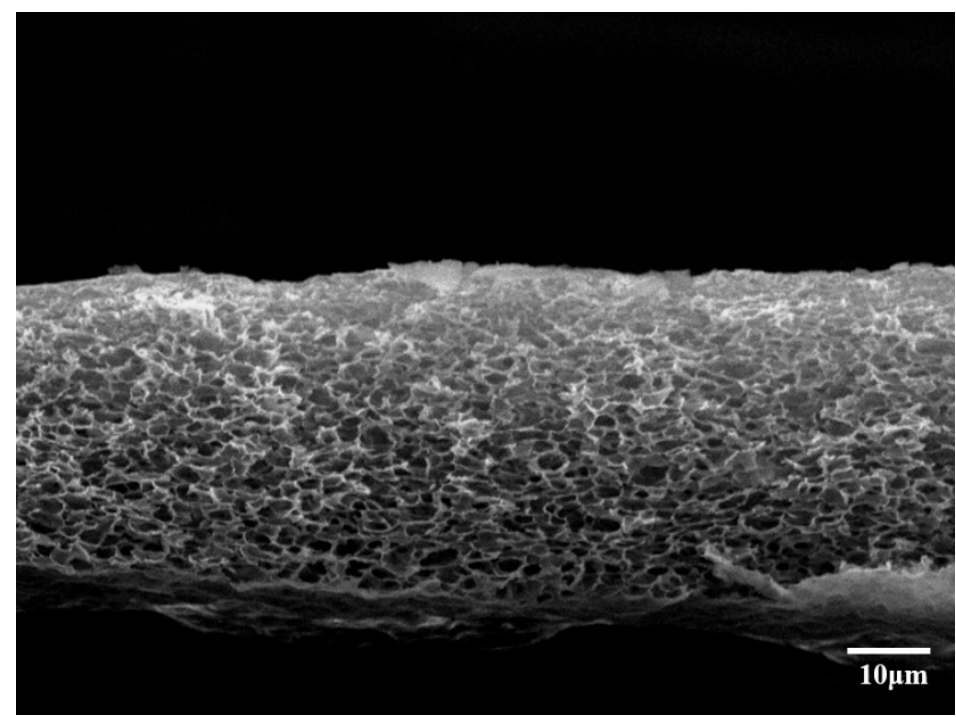

Figure 3. SEM images of 1:0.23 CA/Ni( $\left(\mathrm{NO}_{3}\right)_{2} \cdot 6 \mathrm{H}_{2} \mathrm{O}$ film dissolved in acetone/water ( $w t / w t$ 8:2) after water treatment at 8 bar.

\subsection{Fourier-Transform Infrared (FT-IR) Spectroscopy}

FT-IR spectroscopy was used to investigate the interaction between the carbonyl groups of CA and the nickel salt. Figure 4, which compares the carbonyl peaks of neat $\mathrm{CA}$ and 1:0.23 CA/Ni salt at 0 bar, shows that the peak shifted from 1741 to $1737 \mathrm{~cm}^{-1}$ and broadened. The carbonyl peak of CA before applying water pressure was $1737 \mathrm{~cm}^{-1}$, which shifted to $1741 \mathrm{~cm}^{-1}$ after applying water pressure to the membrane. Therefore, it was demonstrated that most of the nickel(II) nitrate hexahydrate salt was removed after the pores were formed upon application of the water pressure.

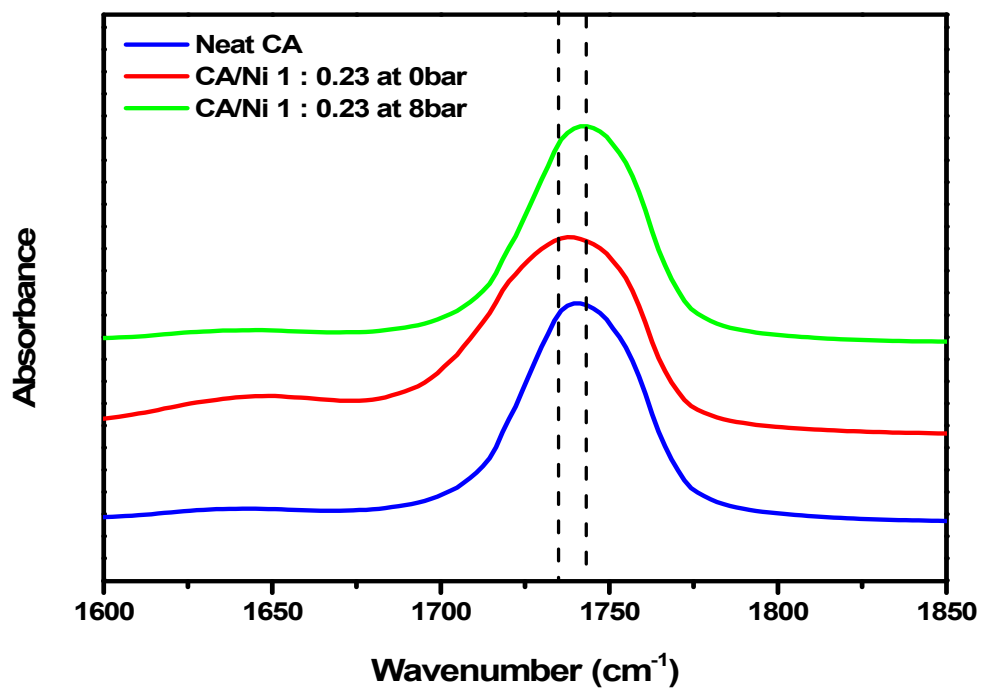

Figure 4. FT-IR spectra of neat CA, 1:0.23 CA/Ni salt at 0 bar and 1:0.23 CA/Ni salt at 8 bar.

As can be seen in Figure 5, when an OIT sample was adsorbed on the 1:0.23 CA/Ni salt membrane at 8 bar, the carbonyl peaks changed either slightly or not at all. When comparing the peaks within the region ranging from 1735 to $1737 \mathrm{~cm}^{-1}$ in Figure 5 and Table 2, a very small area variation of $1.37-6.84 \%$ was observed for OIT concentrations of $1.0 \times 10^{-1}-1.0 \times 10^{-3}$. Therefore, since this membrane did not 
strongly interact with OIT, it can be expected that OIT would easily pass through the column without being adsorbed when using it as a pretreatment membrane for sensing.

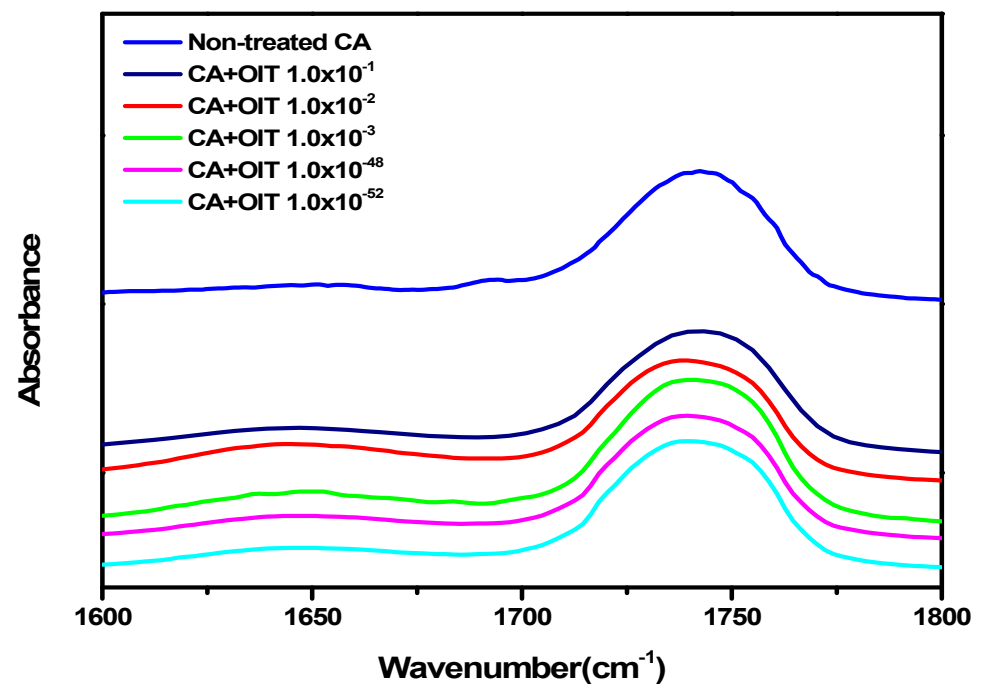

Figure 5. FT-IR spectra for the interaction between the carbonyl groups of the cellulose acetate (CA) polymers with 2-n-octyl-4-isothiazolin-3-one (OIT) at various concentrations.

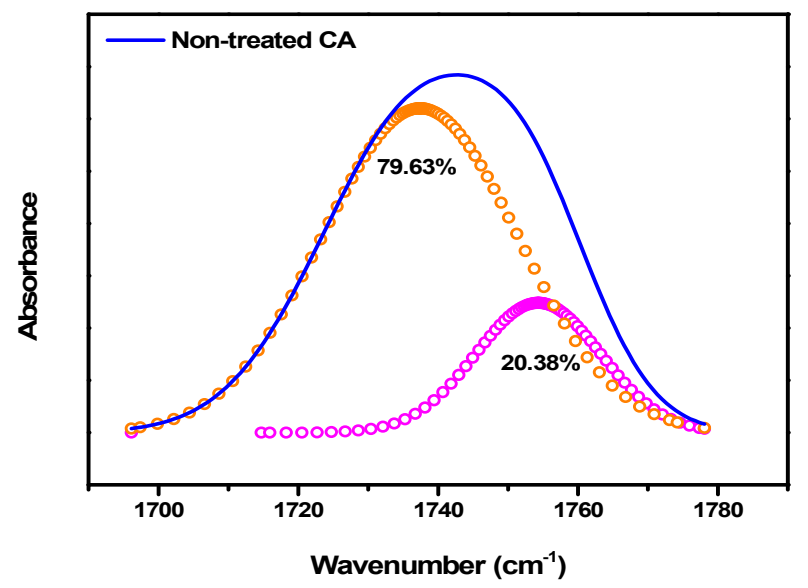

(a)

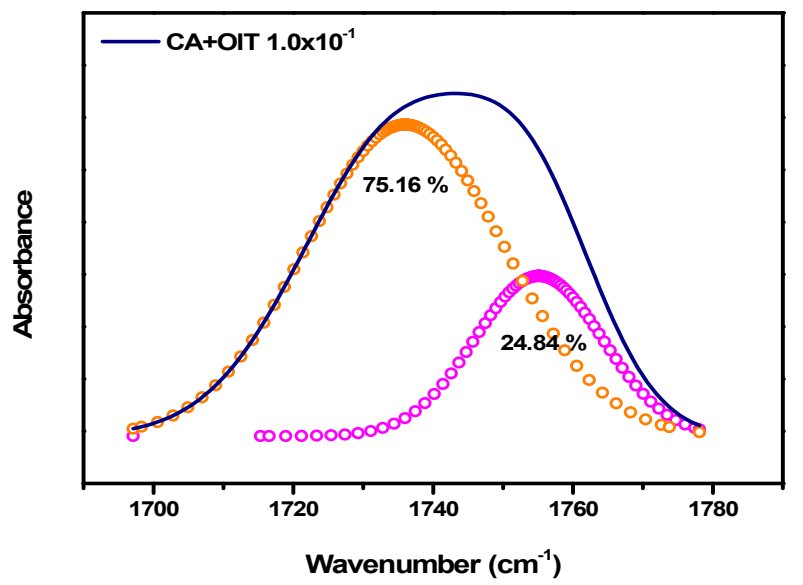

(b) 


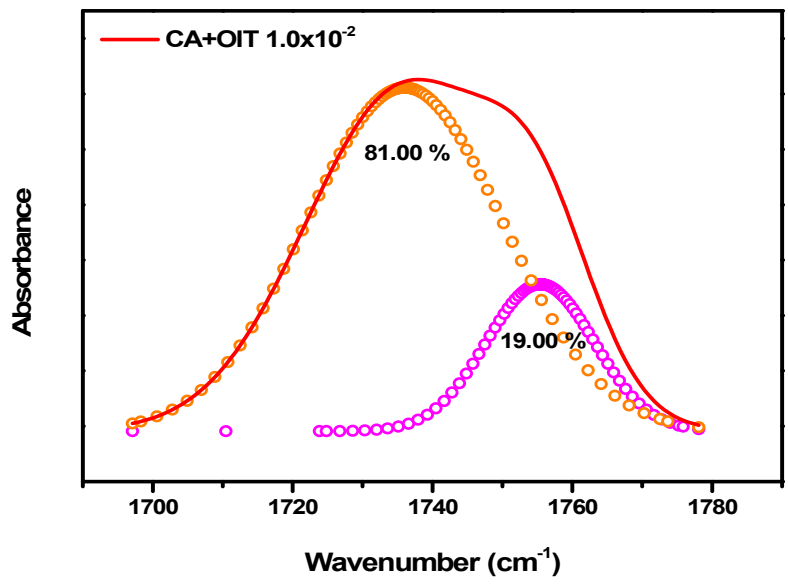

(c)

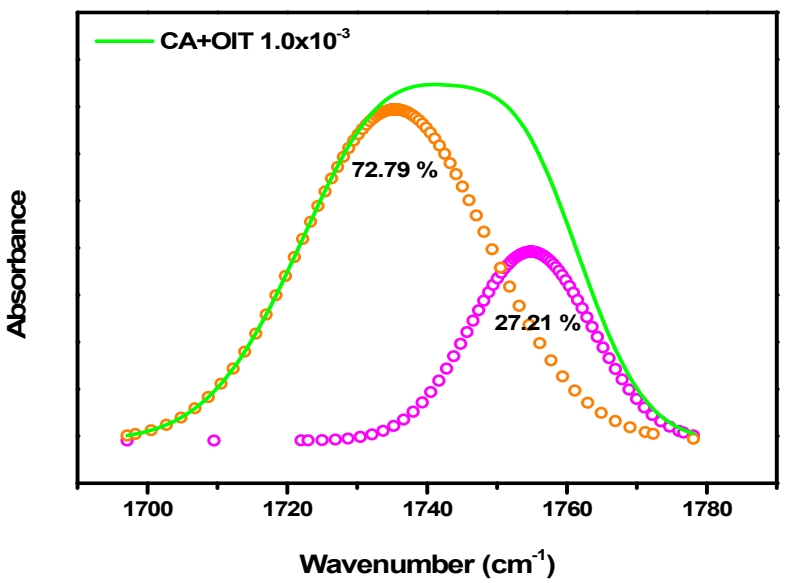

(d)

Figure 5. Deconvolution spectra of (a) neat CA, (b) 1:1.0 $\times 10^{-1} \mathrm{CA} / \mathrm{OIT},(\mathbf{c}) 1: 10 \times 10^{-2} \mathrm{CA} / \mathrm{OIT}$ and (d) $1: 10 \times 10^{-3} \mathrm{CA} / \mathrm{OIT}$.

Table 2. Area ratio of deconvoluted carbonyl peaks at various OIT concentrations.

\begin{tabular}{ccccc}
\hline Peaks & Neat CA & CA/OIT 1:1.0 $\times \mathbf{1 0}^{\mathbf{- 1}}$ & CA/OIT 1:1.0 $\times \mathbf{1 0}^{-\mathbf{2}}$ & CA/OIT 1:1.0 $\times \mathbf{1 0}^{-\mathbf{3}}$ \\
\hline $1735-1737 \mathrm{~cm}^{-1}$ & $79.63 \%$ & $75.16 \%$ & $81.00 \%$ & $72.79 \%$ \\
$1754-1755 \mathrm{~cm}^{-1}$ & $20.37 \%$ & $24.84 \%$ & $19.00 \%$ & $27.21 \%$ \\
\hline
\end{tabular}

\subsection{Thermogravimetric Analysis (TGA)}

In Figure 6, TGA was conducted to explore the plasticization of the polymer matrix and further compare the thermal weight loss before and after the addition of the nickel salt to the membrane, as well as before and after applying the water pressure. When comparing the weight loss of neat $\mathrm{CA}$ and 1:0.23 CA/Ni salt at 0 bar, the degradation temperature of neat CA was approximately $340{ }^{\circ} \mathrm{C}$, while 1:0.23 CA/Ni salt at 0 bar exhibited a weight loss at approximately $240{ }^{\circ} \mathrm{C}$ due to a plasticization effect caused by the nickel(II) nitrate hexahydrate salt. After applying the water pressure, 1:0.23 CA/Ni salt at 8 bar underwent a weight loss at approximately $340{ }^{\circ} \mathrm{C}$, similar to neat CA. Subsequently, water pressure treatment resulted in the formation of pores, and it was confirmed that most of the nickel salt was released. 


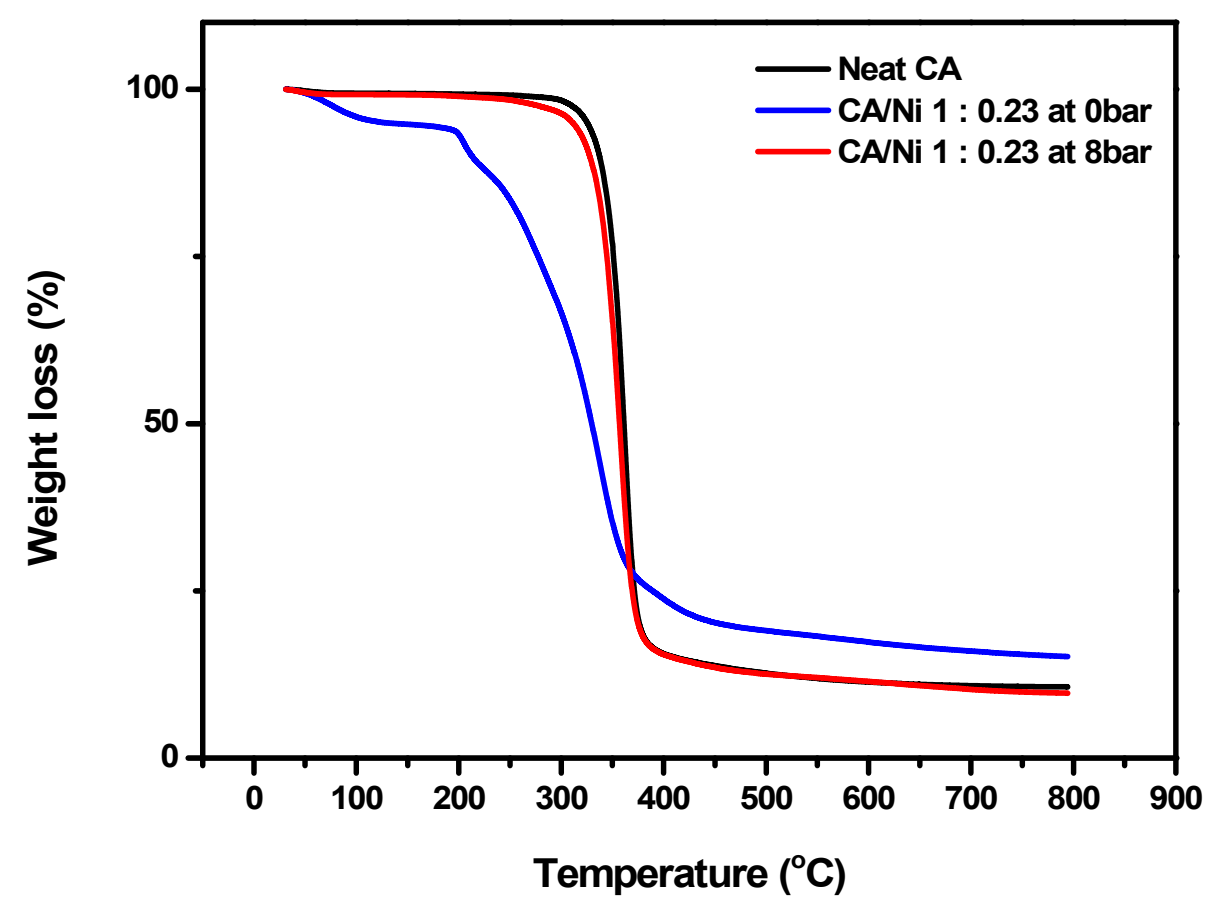

Figure 6. Thermogravimetric curves of neat $\mathrm{CA}, 1: 0.23 \mathrm{CA} / \mathrm{Ni}\left(\mathrm{NO}_{3}\right)_{2} \cdot 6 \mathrm{H}_{2} \mathrm{O}$ at 0 bar and 1:0.23 $\mathrm{CA} / \mathrm{Ni}\left(\mathrm{NO}_{3}\right)_{2} \cdot 6 \mathrm{H}_{2} \mathrm{O}$ at 8 bar.

\section{Conclusions}

In this study, the suitability of a CA-based porous membrane as a pretreatment filter device for the detection of OIT was investigated. The CA polymer is an environment-friendly, low-cost and energy-efficient material. Moreover, CA possesses many hydrophilic functional groups, such as carbonyl and ether groups. By exploiting this feature, hydrophilic impurities can be adsorbed onto the membrane, while hydrophobic substances like OIT can be expected to easily pass through a CA membrane column.

Since the interaction between OIT and the pretreatment membrane was found to be very weak, when OIT mixed with hydrophilic impurities was passed through the membrane, the hydrophilic substances were captured within the CA pores, while OIT easily reached the detection device. FT-IR spectroscopic analysis was used to confirm the extent of OIT adsorption on a 1:0.23 CA/Ni salt membrane after application of the water pressure. In Table 2, since the area difference of the deconvoluted data was closely observed, it could be suggested that the OIT and membrane formed a weak bond. Furthermore, a water uptake experiment was conducted to determine the extent of binding with the hydrophilic groups. It can be concluded that the hydrophilic materials were adsorbed after approximately $6 \mathrm{~h}$, indicating that the membrane could strongly bind with these substances. As a result, the CA membrane column developed herein is suitable as a pretreatment film, since it could adsorb the hydrophilic impurities to a satisfactory extent, while allowing the hydrophobic OIT through.

Author Contributions: S.W.K. led the project, conducted the data analysis, and reviewed the manuscript. S.H.H. performed the experiments, collected the data, and wrote the paper. All authors have read and agreed to the published version of the manuscript.

Funding: This work was supported by the Basic Science Research Program (2020R1F1A1048176) through the National Research Foundation of Korea (NRF), funded by the Ministry of Science, ICT and Future Planning. This work was also supported by a National Research Council of Science \& Technology (NST) grant from the Korean government (MSIT) (No. CRC-14-1-KRICT) and Korea Environment Industry \& Technology Institute (KEITI) through the "Technology Program for establishing biocide safety management" (RE201805019).

Conflicts of Interest: The authors declare no conflict of interest. 


\section{References}

1. Aduenko, A.; Marray, A.; Mendoza-Cortes, J. General theory of adsorption in porous materials: Restricted multilayer theory. ACS Appl. Mater. Interfaces 2018, 10, 13244-13251. [CrossRef] [PubMed]

2. Dorin, R.; Sai, H.; Wiesner, U. Hierarchically porous materials from block copolymers. Chem. Mater. 2014, 26, 339-347. [CrossRef]

3. Vattipalli, V.; Qi, X.; Dauenhauer, P.; Fan, W. Long walks in hierarchical porous materials due to combined surface and configuration diffusion. Chem. Mater. 2016, 28, 7852-7863. [CrossRef]

4. Yao, M.; Tijing, L.; Naidu, G.; Seung-Hyun, K.; Matsuyama, H. A review of membrane wettability for the treatment of silane water developing membrane. Desalination 2020, 479, 114312. [CrossRef]

5. Sheikh, M.; Pazirofteh, M.; Dehghani, M.; Asghari, M. Application of ZnO nanostructure in ceramic and polymeric membranes for water and wastewater technology: A review. Chem. Eng. J. 2020, 391, 123475. [CrossRef]

6. Thompson, A.; Glandt, E. Polymers in random porous material: Structure, thermodynamics and concentrations effects. Macromolecules 1996, 29, 4314-4323. [CrossRef]

7. Seung, R.; Younghyun, C.; Sang, K. Nanocomposite membranes consisting of poly(ethylene oxide)/ionic liquid/ZnO for $\mathrm{CO}_{2}$ separation. J. Ind. Eng. Chem. 2020, 85, 75-80.

8. So, K.; Young, C.; Sang, K. Correlation between functional group and formation of nanoparticles in PEBAX/Ag Salt complexes for olefin separation. Polymers 2020, 12, 667.

9. Qi, S.; Zhifeng, D.; Xiangju, M.; Feng-Shou, X. Porous polymer catalysts with hierarchical structure. Chem. Soc. Rev. 2015, 44, 6018.

10. Selina, H.; Majid, E.; Kolbrun, H.; Margret, B.; Snaeros, A.; Bing, W. Direct membrane filtration for wastewater treatment and resource recovery: A review. Sci. Total Environ. 2020, 710, 136375.

11. Desong, F.; Ming, J.; Jun, W.; Jinhui, L.; Qiang, L. Enhanced heat dissipation in graphite-silver-polyimide structure for electronic cooling. Appl. Therm. Eng. 2020, 168, 114676.

12. Na,H.B.; Zhang, X.F.; Zhang, M.; Deng, Z.P.; Cheng, X.L.; Huo, L.H.; Gao, S. A fast response/recovery ppb-level $\mathrm{H} 2 \mathrm{~S}$ gas sensor based on porous $\mathrm{CuO} / \mathrm{ZnO}$ heterostructural tubule via confined effect of absorbent cotton. Sens. Actuators B Chem. 2019, 297, 126816. [CrossRef]

13. Yuchao, Z.; Yigen, W.; Guangshun, W.; Zhongbao, W.; Qiullin, T.; Libo, Z.; Dezhi, W. A flexible capacitive pressure sensor based on an electrospun polyimide nanofiber membrane. Org. Electron. 2020, 84, 105759.

14. Jincheng, D.; Shanshan, Y.; Jiefeng, P.; Yu, Z.; Arcadio, S.; Jiangnan, S. A novel nanofiltration membrane inspired by an asymmetric porous membrane for selective fractionation of monovalent anions in electrodialysis. RSC Adv. 2018, 8, 30502.

15. Yaqiu, L.; Linli, G.; Min, X.; Shuanjin, W.; Shan, R.; Dongmei, H.; Yuezhong, M. Strategies for inhibiting anode dendrite growth in lithium-sulfur batteries. J. Mater. Chem. A Mater. 2020, 8, 4629.

16. Shing, P.; Yuxiang, W.; Dan, Z. Scalable and sustainable synthesis of advanced porous materials. ACS Sustain. Chem. Eng. 2019, 7, 3647-3670.

17. Giovanni, C.; Rafael, F.; Anne, G.; Francesso, R.; Florenza, Q. Mesoporous materials for antihydrogen production. Chem. Soc. Rev. 2013, 42, 3821.

18. Arshad, H.; Dan, L.; Yang, L.; Hongzhang, Z.; Huamin, Z. Porous membrane with improved dendrite resistance for high-performance lithium metal-based battery. J. Memb. Sci. 2020, 605, 118108.

19. Xiaourui, R.; Lina, Z.; Xuefu, C.; Yuyang, C.; Yunqi, L.; Huanhuan, L.; Hui, C.; Hongxiang, H.; Jianguo, L.; Jingshuai, Y. Quaternary ammonium groups grafted polybenzimidazole membranes for vanadium redox flow battery applications. J. Power Sources 2020, 457, 228037.

20. Alrammouz, R.; Podlecki, J.; Vena, A.; Garcia, R.; Abboud, P.; Habchi, R.; Sorli, B. Highly porous and flexible capacitive humidity sensor based on self-assembled graphene oxide sheets on a paper substrate. Sens. Actuators B Chem. 2019, 298, 126892. [CrossRef]

21. Sufang, Z.; Wenhao, J.; Yiwen, L.; Xueli, Y.; Peng, S.; Fangmeng, L.; Xu, Y.; Yang, G.; Xishuang, L.; Jian, M.; et al. Highly-sensitivity acetone sensors based on spinel-type oxide (NiFe2O4) through optimization of porous structure. Sens. Actuators B Chem. 2019, 291, 266-274.

22. Peng, T.; Yao, J.; Xiao-Qin, L.; Lin-Bing, S. Making porous materials respond to visible light. ACS Energy Lett. 2019, 4, 2656-2667. 
23. Mohammed, R.; Alam, M.; Abdullah, A.; Jamal, U. 3-Methoxyphenol chemical sensor fabrication with $\mathrm{Ag}_{2} \mathrm{O} / \mathrm{CB}$ nanocomposites. New J. Chem. 2020, 44, 2001.

24. Kopytin, A.; German, K.; Zhizhin, K.; Safonov, A.; Zhukov, A.; Shpigun, L. A tetradecylphosphonium compounds-based membrane sensor for potentiometric quantitation of pertechnetate-ions in cementitious radioactive waste. Sens. Actuators B Chem. 2020, 310, 127853. [CrossRef]

25. Bo, Z.; Yan, W.; Xiaoning, M.; Zhanying, Z.; Shifang, M. High response methane sensor based on Au-modified hierarchical porous nanosheets-assembled ZnO microspheres. Mater. Chem. Phys. 2020, 250, 123027.

26. Yanni, L.; Zhi, W.; Song, Z.; Xiaochang, C.; Nan, L.; Jixiao, W.; Shichang, W. Hydrothermal pretreatment: A simple method for dry substrate membrane regeneration. Sep. Purif. Technol. 2018, 199, 152-160.

27. Neha, T.; Chandrabhan, P.; Rachana, Y.; Neeraj, K.J. First-principles design of nano-porous graphene membranes for efficient separation of halogen gases. Diam. Relat. Mater. 2020, 108, 107911.

28. Lei, W.; Jiangtao, J.; Muhammad, F.; Yuyang, T.; Guangshan, Z. Fabrication of triazine-based Porous Aromatic Framework (PAF) membrane with structural flexibility for gas mixtures separation. J. Ind. Eng. Chem. 2018, 67, 373-379.

29. Anna, O.; Vladimir, V.; Ilya, B.; Stepan, B.; Alexey, V. Polysulfone porous hollow fiber membranes for ethylene-ethane separation in gas-liquid membrane contactor. Sep. Purif. Technol. 2017, 183, 162-172.

30. Jansen, S.; Kuo-Jen, H.; Chiao-Wei, C.; Hung-Yuan, T.; Allen, H.; Chien-Hua, C.; Tung-Wen, C.; Kuo-Lun, T. Fenton oxidation-based cleaning technology for powdered activated carbon-precoated dynamic membranes used in microfiltration seawater pretreatment system. J. Memb. Sci. 2019, 591, 117298.

31. Woong, L.; Do, K.; Woo, J.; Sang, K.; Seok, K.; Sang, K. Facile control of nanoporsity in cellulose acetate using nickel(II) nitrate additive and water pressure treatment for highly efficient battery gel separators. Sci. Rep. 2017, 7, 1287.

32. Tatsuo, K. Water adsorption properties controlled by coating/filling ordered mesoporous silica inside cellulose membranes. Chem. Phys. 2013, 15, 15056.

Publisher's Note: MDPI stays neutral with regard to jurisdictional claims in published maps and institutional affiliations.

(C) 2020 by the authors. Licensee MDPI, Basel, Switzerland. This article is an open access article distributed under the terms and conditions of the Creative Commons Attribution (CC BY) license (http://creativecommons.org/licenses/by/4.0/). 